University of Wollongong

Research Online

Faculty of Engineering and Information

Faculty of Engineering and Information

Sciences - Papers: Part A

Sciences

$1-1-2014$

\title{
Rejection of small solutes by reverse osmosis membranes for water reuse applications: a pilot-scale study
}

Takahiro Fujioka

University of Wollongong, takahiro@uow.edu.au

Kha L. Tu

University of Wollongong, lkt883@uowmail.edu.au

Stuart J. Khan

University of New South Wales, s.khan@unsw.edu.au

James A. McDonald

University of New South Wales

Annalie Roux

Seqwater

See next page for additional authors

Follow this and additional works at: https://ro.uow.edu.au/eispapers

Part of the Engineering Commons, and the Science and Technology Studies Commons

Research Online is the open access institutional repository for the University of Wollongong. For further information contact the UOW Library: research-pubs@uow.edu.au 


\title{
Rejection of small solutes by reverse osmosis membranes for water reuse applications: a pilot-scale study
}

\author{
Abstract \\ $\mathrm{N}$-nitrosamines and boron are small solutes of particular concern during water recycling applications. \\ Here, we evaluated the rejection of seven $\mathrm{N}$-nitrosamines and boron under a range of operating conditions \\ and feed solution characteristics. The evaluationwas conducted using a pilot-scale reverse osmosis (RO) \\ system to appropriately simulate hydrodynamic conditions of full-scale RO installations. The rejection of \\ seven $\mathrm{N}$-nitrosamines by the pilot RO system varied significantly in the range from 31 to $94 \%$, and \\ rejection increased in the increasing order of their molecular weight. Rejection values obtained from this \\ pilot-scale study were lower than those previously reported in laboratory-scale studies. These \\ discrepancieswere attributed to a difference in RO system operating condition (i.e. recovery) between the \\ pilot-scale study (25\%) and laboratory-scale study (b0.1\%). Nevertheless, rejection data reported here \\ validate the recent findings fromlaboratory-scale studies with respect to the impact of permeate flux, feed \\ temperature and feed $\mathrm{pH}$ on separation efficiencies of $\mathrm{N}$-nitrosamines. Data obtained from this pilot-scale \\ study also validate the strong correlation between boron and NDMA rejection at or below pH 8 regardless \\ of operating conditions and feed solution characteristics. The results suggest that boron rejection can be \\ used as a surrogate for NDMA rejection in full-scale RO installations.

\section{Disciplines} \\ Engineering | Science and Technology Studies

\section{Publication Details} \\ Fujioka, T., Tu, K. L., Khan, S., McDonald, J., Roux, A., Poussade, Y., Drewes, J. \& Nghiem, L. (2014). \\ Rejection of small solutes by reverse osmosis membranes for water reuse applications: A pilot-scale \\ study. Desalination, 350 28-34.

\section{Authors} \\ Takahiro Fujioka, Kha L. Tu, Stuart J. Khan, James A. McDonald, Annalie Roux, Yvan Poussade, Jörg E. \\ Drewes, and Long D. Nghiem
}




\title{
Rejection of small solutes by reverse osmosis membranes for water reuse applications: A pilot-scale study
}

\author{
Revised manuscript submitted to
}

\section{Desalination}

June 2014

Takahiro Fujioka ${ }^{1}$, Kha L. Tu ${ }^{1}$, Stuart J. Khan ${ }^{2}$, James A. McDonald ${ }^{2}$, Annalie Roux ${ }^{3}$, Yvan Poussade ${ }^{4}$, Jörg E. Drewes ${ }^{2,5}$, Long D. Nghiem ${ }^{1, *}$

${ }^{1}$ Strategic Water Infrastructure Laboratory, School of Civil Mining and Environmental Engineering, The University of Wollongong, NSW 2522, Australia

${ }^{2}$ UNSW Water Research Centre, School of Civil and Environmental Engineering, The University of New South Wales, NSW 2052, Australia

${ }^{3}$ Seqwater, Level 2, 240 Margaret Street, Brisbane, QLD 4000, Australia

${ }^{4}$ Veolia Water Australia, Level 15, 127 Creek Street, Brisbane, QLD 4000, Australia

${ }^{5}$ Chair of Urban Water Systems Engineering, Technische Universität München, 85748 Garching, Germany

\footnotetext{
* Corresponding author: Long Duc Nghiem, Email: longn@uow.edu.au, Ph +61 242214590
} 


\section{Abstract}

2 N-nitrosamines and boron are small solutes of particular concern during water recycling 3 applications. Here, we evaluated the rejection of seven $\mathrm{N}$-nitrosamines and boron under a 4 range of operating conditions and feed solution characteristics. The evaluation was conducted 5 using a pilot-scale reverse osmosis (RO) system to appropriately simulate hydrodynamic 6 conditions of full-scale RO installations. The rejection of seven N-nitrosamines by the pilot 7 RO system varied significantly in the range from 31 to $94 \%$, and rejection increased in the 8 increasing order of their molecular weight. Rejection values obtained from this pilot-scale 9 study were lower than those previously reported in laboratory-scale studies. These 10 discrepancies were attributed to a difference in RO system operating condition (i.e. recovery) 11 between the pilot-scale study $(25 \%)$ and laboratory-scale study $(<0.1 \%)$. Nevertheless, 12 rejection data reported here validate recent findings from laboratory-scale studies with 13 respect to the impact of permeate flux, feed temperature and feed $\mathrm{pH}$ on separation 14 efficiencies of $\mathrm{N}$-nitrosamines. Data obtained from this pilot-scale study also validate the 15 strong correlation between boron and NDMA rejection at or below $\mathrm{pH} 8$ regardless of 16 operating conditions and feed solution characteristics. The results suggest that boron rejection 17 can be used as a surrogate for NDMA rejection in full-scale RO installations.

18 Keywords: Boron; N-nitrosodimethylamine (NDMA); N-nitrosamines; spiral wound 19 membrane elements; reverse osmosis (RO); water reuse. 


\section{Introduction}

21 Water reuse is an increasingly important strategy in many parts of the world to supplement

22 drinking water resources [1]. Municipal wastewater is abundantly available in the urban

23 environment where water demand is high. In a planned indirect potable water reuse scheme,

24 secondary or tertiary treated wastewater is reclaimed using advanced treatment technologies to produce high quality water. Reclaimed water can potentially contain pathogenic agents and traces of organic contaminants which may cause adverse impact on human health. Thus, water reuse is subjected to a stringent set of regulations for public health protection. Among a series of water treatment processes in a water reclamation plant, reverse osmosis (RO) filtration serves as an efficient barrier for removing most trace organic chemicals [2]. Nevertheless, a small compound, N-nitrosodimethylamine (NDMA) has been detected in RO permeate at a higher concentration than its regulatory value (i.e. $10 \mathrm{ng} / \mathrm{L}$ ) [3, 4]. Moreover, NDMA rejection evaluated in full-scale plants has been reported to be variable and therefore difficult to predict (10-55\%) [3-6].

34 NDMA is frequently detected in secondary treated wastewater [7]. In addition, NDMA concentration can increase during chloramination, which is commonly employed prior to RO filtration. The other N-nitrosamines that can occur in treated wastewater include Nnitrosomethylethylamine (NMEA), N-nitrosopyrrolidine (NPYR), N-nitrosodiethylamine (NDEA), N-nitrosopiperidine (NPIP), N-nitrosomorpholine $\quad$ (NMOR), $\quad \mathrm{N}$ nitrosodipropylamine (NDPA), N-nitrosodi-n-butylamine (NDBA) [8-10]. NDMA and some other N-nitrosamines have been classified as probable human carcinogens by the US EPA [11]. The permeation of NDMA and other N-nitrosamines through RO membranes has been investigated in many laboratory-scale studies using small membrane coupons [12-16]. These laboratory-scale studies suggest that NDMA rejection by RO membranes is affected by changes in operating conditions (e.g. feed temperature and permeate flux). Nevertheless, findings obtained from these laboratory-scale studies employing flat-sheet membrane specimen cannot be directly used to accurately simulate hydrodynamic conditions of fullscale RO system. Despite the differences between small membrane coupons and spiral wound membrane elements, investigations evaluating the rejection of $\mathrm{N}$-nitrosamines using pilotscale RO systems remain scarce [5] and no previous pilot-scale RO studies have been 
conducted to mechanistically elucidate the impact of various operating conditions on $\mathrm{N}$ nitrosamine rejection.

52

Regularly monitoring N-nitrosamines in aqueous solution at parts per trillion levels is another challenge for most water authorities. Analysis of N-nitrosamine concentrations is generally carried out using an analytical method which comprises solid phase extraction followed by gas chromatography or high pressure liquid chromatography with tandem mass spectrometry detector [17]. The analysis of N-nitrosamines at parts per trillion levels is expensive and not always readily available. Thus, any alternative indicators that simulate the rejection of $\mathrm{N}$ nitrosamines, in particular NDMA, by reverse osmosis could be very useful for monitoring purposes. A recent laboratory-scale study by Tu et al. [18] reported that boron rejections by RO membranes under a range of a specific operating condition (i.e. permeate flux or feed temperature) correlate with NDMA rejection. The similarity in the rejection behaviour between boron and NDMA is very likely due to their similar physicochemical characteristics. In fact, both boron (as a boric acid) and NDMA molecules are small (62 g/mol and $74 \mathrm{~g} / \mathrm{mol}$, respectively) and uncharged under operating conditions representative of RO installations (i.e. $\mathrm{pH}$ 6-8) $[19,20]$. It is noteworthy that boron in reclaimed water is also of great concern in places where reclaimed water is used for irrigation. Unlike NDMA, boron is abundantly detected in treated wastewater at $0.3-4 \mathrm{mg} / \mathrm{L}$ [21] and several commercially available online boron analysers have parts per billion to trillion sensitivity. Thus, boron rejection can potentially be used as a surrogate to estimate NDMA rejection. The use of boron as an NDMA surrogate will not replace compliance monitoring of NDMA in the final product water. However, it will facilitate better system design and reduce the number of analyses, and hence the cost associated with ongoing NDMA monitoring.

To date, the potential use of boron rejection as a surrogate of NDMA rejection has only been demonstrated by laboratory scale experiments using a small membrane sample. The hydraulic and hydrodynamic conditions as well as operating conditions (i.e. water recovery) between a lab-scale RO set-up using small flat sheet membrane coupons and pilot- and full-scale installations using spiral wound membrane elements can differ significantly. Thus, it is warranted to validate whether the observed correlation between boron and NDMA rejections also applies to RO systems employing spiral-wound elements. The aim of this study was to demonstrate the rejection of $\mathrm{N}$-nitrosamines and boron using a pilot-scale RO system 
81 simulating hydrodynamic conditions of full-scale RO installations under a range of different operating conditions (i.e. permeate flux, feed $\mathrm{pH}$ and feed temperature).

\section{2. Materials and methods}

\subsection{Chemicals}

Analytical grade N-nitrosamines and boric acid (Table 1) were purchased from SigmaAldrich (St Louis, MO, USA). These N-nitrosamines include NDMA, NMEA, NPYR, NDEA, NPIP, NMOR and NDPA. A stock solution was prepared in pure methanol at 10 $\mathrm{mg} / \mathrm{L}$ of each $\mathrm{N}$-nitrosamine. Deuterated N-nitrosamines used for analysis were supplied by CDN isotopes (Pointe-Claire, Quebec, Canada) and these chemicals include Nnitrosodimethylamine-D6, N-nitrosomethylethylamine-D3, N-nitrosopyrrolidine-D8, Nnitrosodiethylamine-D10, N-nitrosopiperidine-D10, N-nitrosomorpholine-D8 and Nnitrosodipropylamine-D14. A surrogate stock solution of $100 \mu \mathrm{g} / \mathrm{L}$ of each deuterated $\mathrm{N}$ nitrosamine was prepared in pure methanol. These stock solutions were kept at $-18{ }^{\circ} \mathrm{C}$ in the dark and were used within 1 month of preparation. Analytical grade $\mathrm{NaCl}, \mathrm{CaCl}_{2}$ and $\mathrm{NaHCO}_{3}$ were obtained from Ajax Finechem (Taren Point, NSW, Australia) and used as the background electrolytes during the filtration experiments.

\section{[Table1]}

\subsection{Pilot-scale filtration system and experimental protocols}

99 The pilot-scale RO filtration system used for this investigation has a permeate design flow of

$100 \quad 0.72 \mathrm{~m}^{3} / \mathrm{h}$ (Figure 1). The system consists of three 4 inch glass-fibre pressure vessels, a feed 101 reservoir, a centrifugal feed pump (CRN 3-25, Grundfos, Bjerringbro, Denmark), and variable flow meters. Pipe lines in the feed stream were made of stainless steel and those in the permeate stream were made of PVC. Each pressure vessel could hold one RO membrane element $(4$ inch $\times 40$ inch). Feed solution temperature was controlled in the feed reservoir using stainless steel heat exchanging pipes connected to a chillier unit (Aqua Cooler S360PD-

106 CT, Chester Hill, NSW, Australia). The TFC-HR membrane (TFC 4040HR, Koch Membrane

107 Systems, San Diego, CA, USA) used in the study is a composite polyamide RO membrane 108 designed for brackish water treatment with a membrane area of $7.9 \mathrm{~m}^{2} /$ element. 
109 Prior to the pilot-scale filtration experiment, $200 \mathrm{~L}$ of RO feed solution was prepared in the

110 feed tank. RO feed solutions used for this investigation were conditioned to obtain $20 \mathrm{mM}$

$111 \mathrm{NaCl}, 1 \mathrm{mM} \mathrm{CaCl}$ and $1 \mathrm{mM} \mathrm{NaHCO}_{3}$ in deionised water or actual microfiltration (MF)

112 permeate which was collected from a local full-scale water recycling plant in Australia. The

113 TOC, conductivity, and $\mathrm{pH}$ of the MF permeate were $9.6 \mathrm{mg} / \mathrm{L}, 0.91 \mathrm{mS} / \mathrm{cm}$, and 6.9 ,

114 respectively. In addition, $\mathrm{N}$-nitrosamines and boric acid were dosed into the feed solution at

115 approximately $250 \mathrm{ng} / \mathrm{L}$ of each $\mathrm{N}$-nitrosamine and $5 \mathrm{mg} / \mathrm{L}$ of boron. Subsequently, the pilot

116 RO system was continuously operated under standard conditions (permeate flux $20 \mathrm{~L} / \mathrm{m}^{2} \mathrm{~h}$,

117 feed temperature $20{ }^{\circ} \mathrm{C}$, feed $\mathrm{pH} 8.0$ ) for 15 hours prior to any sampling events. The

118 concentrate and permeate solutions were recirculated into the feed tank. The overall system

119 recovery was maintained at $25 \%$ throughout the experiments. For N-nitrosamine analysis,

$120200 \mathrm{~mL}$ of RO feed and permeate samples were collected in amber glass bottles and the N-

121 nitrosamine surrogate stock solution was dosed into each sample to obtain $50 \mathrm{ng} / \mathrm{L}$ of each

122 isotope labelled $\mathrm{N}$-nitrosamine. From the same sampling point, $20 \mathrm{~mL}$ sample was also

123 collected in plastic bottles for the analysis of boron and sodium ions. Experiments with

124 variable operating conditions started with low permeate flux of $10 \mathrm{~L} / \mathrm{m}^{2} \mathrm{~h}$, which was

125 increased stepwise to $30 \mathrm{~L} / \mathrm{m}^{2} \mathrm{~h}$. When operating conditions were changed, sampling was

126 conducted after at least 1 hour of system operation. Experiments with variable feed

127 temperature were first evaluated under low feed temperature $\left(10^{\circ} \mathrm{C}\right)$ and the feed temperature

128 was incrementally increased to $35^{\circ} \mathrm{C}$. Experiments with variable feed $\mathrm{pH}$ were conducted by 129 adjusting feed $\mathrm{pH}(5-9.5)$ with a dose of either $\mathrm{HCl}$ or $\mathrm{NaOH}$.

[Figure 1]

\section{2.3. Analytical technique}

132 N-nitrosamine concentrations in the RO feed and permeate were determined using an 133 analytical method reported by McDonald et al. [17] and a brief summary is provided here. N134 nitrosamines in each sample were first extracted by solid phase extraction method using 135 Supelclean $^{\mathrm{TM}}$ Coconut Charcoal SPE cartridges (Supelco, St Louis, MO, USA). The 136 determination of N-nitrosamine concentrations were carried out using an Agilent 7890A gas 137 chromatograph coupled with an Agilent $7000 \mathrm{~B}$ triple quadrupole mass spectrometer. In brief, 138 boron concentration was determined using an inductively-coupled plasma-mass spectrometer 139 (7500Cs, Agilent Technologies, Wilmington, DE, USA). The details of boron and sodium ion 
140 analysis have been described by a previous study [22]. Calibration of the analysis was 141 conducted using a Merck ICP multi-element standard solution.

\section{3. Results and discussion}

\section{3.1. N-nitrosamine and boron rejection}

144 Transport of neutral solutes across $\mathrm{RO}$ membranes involves the partitioning of the solute into 145 the membrane active skin layer followed by diffusion to the permeate side. In principal, 146 solutes larger than free-volume holes of the membrane active skin layer cannot enter the 147 membrane matrix. Once smaller solutes have entered the membrane polymeric matrix, their 148 transport across the active skin layer is dependent on a chemical potential but is essentially 149 independent of the feed pressure [23]. The diffusivity within the membrane matrix can 150 decrease with increasing the solute size (i.e. Stokes radius) as suggested by Kiso et al. [24]. 151 This indicates that the diffusivity of large solutes within the membrane is more likely to be 152 slower than that of small solutes. In fact, $\mathrm{N}$-nitrosamine rejection by RO membranes is mostly governed by size exclusion as reported in previous laboratory-scale studies [12, 25], suggesting that smaller N-nitrosamines permeate through RO membranes more easily than larger $\mathrm{N}$-nitrosamines.

156 As expected, the rejection of N-nitrosamines by the pilot RO system varied significantly in 157 the range from 31 to $94 \%$ and rejection generally increased in the increasing order of the 158 molecular weight of N-nitrosamines with the exception of NMOR (Figure 2). The rejection 159 values of $\mathrm{N}$-nitrosamines and boron observed in this pilot-scale study differed from those 160 reported in previous laboratory-scale studies $[12,18]$. For example, the rejections of NDMA 161 and boron obtained in this pilot-scale study (31 and 27\%, respectively) were lower than those 162 reported in the laboratory-scale studies (46\% and 57\%, respectively) (Figure 2). Likewise, the 163 rejections of the other N-nitrosamines by spiral wound membranes (pilot-scale study) were 2$16419 \%$ in rejection value lower than those by flat sheet membranes. The variation in rejection 165 between the laboratory- and pilot-scale systems was negligible for higher molecular weight 166 N-nitrosamines (i.e. NPIP and NDPA) with the exception of NMOR (Figure 2). Results 167 reported here suggest that there can be a large variation between the rejections of these low molecular weight compounds obtained from laboratory- and pilot-scale experiments. 
169 It is noteworthy that the pilot-scale RO system was operated under a similar condition (i.e. 20

$170 \mathrm{~L} / \mathrm{m}^{2} \mathrm{~h}$ average permeate flux and $20{ }^{\circ} \mathrm{C}$ feed temperature) and with the same feed water (i.e.

$17120 \mathrm{mM} \mathrm{NaCl}, 1 \mathrm{mM} \mathrm{NaHCO} 3,1 \mathrm{mM} \mathrm{CaCl}_{2}$, and feed $\mathrm{pH}$ 8.0) compared to the previous

172 laboratory-scale studies [12, 18]. A notable difference in operating conditions between the

173 pilot- and laboratory-scale studies was RO system recovery ( 25 and $<0.1 \%$, respectively). In

174 general, the rejection of trace organic chemicals by nanofiltration/RO membranes decreases

175 with increasing system recovery [26, 27]. When increasing system recovery solute

176 concentrations increase toward the exit of the feed stream due to the accumulation of rejected

177 solutes [27]. Moreover, with increasing system recovery a reduction in cross flow velocity

178 and subsequent increase in concentration polarisation occur toward the tail-end elements of

179 the latest stage of a membrane skid. The difference in membrane geometry between the

180 laboratory- and pilot-scale systems can also be another factor. Although clarifying the

181 contribution of these three factors described above is beyond the scope of this study, one or

182 several of these factors are likely to have resulted in different solute rejections between these 183 two studies.

[Figure 2]

\subsection{Effects of $R O$ feed solution chemistry and operating conditions}

\section{3.2.1. Permeate flux}

187 Increasing permeate flux resulted in an increase in the rejection of N-nitrosamines, sodium 188 ion and boron (Figure 3a). The observed solution rejection increase can be attributed to the larger increase in water compared to solute transport through $\mathrm{RO}$ membranes as can be described by the irreversible thermodynamic model [23]. Of the seven N-nitrosamines used in this investigation, three N-nitrosamines with the lowest molecular weight (i.e. NDMA and

192 NMEA, NPYR) exhibited a significant increase in rejection (approximately 20\%) when 193 permeate flux increased from 10 to $30 \mathrm{~L} / \mathrm{m}^{2} \mathrm{~h}$ (Figure $3 \mathrm{a}$ ). Similarly, boron rejection also 194 increased by approximately $24 \%$ for the same change in permeate flux (Figure $3 b$ ). Changes 195 in NDMA and boron rejection obtained from this pilot-scale study were similar to those 196 reported in previous laboratory-scale studies [12,18] where the rejection of NDMA and 197 boron increased by approximately 21 and $28 \%$, respectively. The increase in the rejection of 198 the other N-nitrosamines obtained from this pilot-scale study (2-11\% in rejection) was 199 smaller than that of the two smallest compounds (i.e. boron and NDMA). The rejection of 
sodium ion was high (96-98\%) despite its small molecule size (molecular weight $23 \mathrm{~g} / \mathrm{mol}$ )

201 (Figure 3b). This is because sodium ions are present in hydrate form $\left(\mathrm{Na}^{+}-6 \mathrm{H}_{2} \mathrm{O}\right)$ in a pH 8 202 aqueous solution, and electrostatic interactions occurring between sodium ion and 203 membranes enhance the rejection of sodium ions.

204 Full-scale RO systems are usually operated at an overall permeate flux of approximately 18205 $20 \mathrm{~L} / \mathrm{m}^{2} \mathrm{~h}$ [28]. Nevertheless, the permeate flux range of 10 to $30 \mathrm{~L} / \mathrm{m}^{2} \mathrm{~h}$ was selected to account for the distribution of local permeate flux within the system. It is noteworthy that the local permeate flux of each of the three elements differed slightly from average (system) flux (Table 2). In a full-scale RO plant, each pressure vessel usually holds 6 or 7 membrane elements. Consequently, distribution of the local permeate flux within a pressure vessel can

210 be larger than that shown Table 2. This is demonstrated by computer simulation using the 211 IMSDesign software from Hydranautics (Table 3).

\section{[Table 2]}

\section{[Table 3]}

\section{3.2.2. Feed temperature}

216 Changes in feed temperature considerably affected the rejection of all compounds selected in 217 this investigation. For example, when feed temperature increased from 10 to $35^{\circ} \mathrm{C}$, the two 218 smallest compounds (i.e. NDMA and boron) exhibited a considerable drop in rejection from 219 approximately $40 \%$ to negligible level $(<10 \%$ ) (Figure 4a,b). Other N-nitrosamines also 220 exhibited a moderate to large decrease in rejection with increasing temperature, but the 221 impact was less pronounced with increasing molecular weight. The impact of temperature on 222 rejection observed from this pilot-scale study was generally similar to those reported in 223 previous laboratory-scale studies $[12,18]$.

224 The effects of feed temperature on the rejection of N-nitrosamines and boron were also 225 investigated using the MF permeate. The rejection of NDMA and boron in the MF permeate 226 were found to be approximately $20 \%$ higher than those in the clean solution for all feed 227 temperatures evaluated (Figures 4 and 5). It is noted that the difference in conductivity (or 
ionic strength) between the clean (synthetic) solution and MF permeate (approximately 0.9 and $2.4 \mathrm{mS} / \mathrm{cm}$, respectively) is not expected to assert any considerable influence on NDMA

230 and boron rejection as reported in previous studies $[12,22]$. On the other hand, the TOC 231 concentration of the MF permeate was $9.6 \mathrm{mg} / \mathrm{L}$. The presence of bulk organic matter in the 232 feed or on membrane surface might explain for the better NDMA and boron rejection 233 obtained from the MF permeate compared to those from a clean (synthetic) solution. In fact, a 234 previous laboratory-scale study [13] has reported a considerable increase in NDMA rejection 235 (from $34 \%$ to $73 \%$ ) due to fouling which was simulated using sand-filtered tertiary wastewater.

237 The decreased rejection can occur because the active skin layer of RO membranes acts as a separation layer and its physicochemical characteristics can change by modifying feed solution characteristics including feed temperature [29]. In addition, permeability coefficient of solutes increases when feed temperature increases which results in a decrease in solute rejection [30]. The results obtained here suggest for wastewater in cold climates (e.g. $10{ }^{\circ} \mathrm{C}$ ), the rejection of NDMA and boron can be expected to be moderate (approximately $40 \%$ ) and the rejection of the other $\mathrm{N}$-nitrosamines can be very high $(>80 \%)$. On the other hand, in warm locations where wastewater temperature might reach $30-35{ }^{\circ} \mathrm{C}$, N-nitrosamines may exhibit a large variation in rejection and NDMA and boron possibly resulting in negligible 246 rejection.

\subsubsection{Feed $\mathrm{pH}$}

250 Changes in feed $\mathrm{pH}$ did not significantly affect the rejection of N-nitrosamines. For example, 251 a large shift in feed $\mathrm{pH}$ (from 5 to 9.5) resulted in a small increase in NDMA rejection (from 25229 to $38 \%$ ) (Figure 6a). The impact of the changes in feed $\mathrm{pH}$ on the rejection of the other N253 nitrosamines was negligible which is consistent with that obtained from a previous 254 laboratory-scale study [12]. Nevertheless, a different rejection trend was observed for boron at high $\mathrm{pH}$. Boron rejection in feed solution of $\mathrm{pH} 9.5$ reached as high as $72 \%$ while boron rejection at the other $\mathrm{pH}(5-8)$ was as low as $27-32 \%$ (Figure $6 \mathrm{~b}$ ). As the solution $\mathrm{pH}$ increases beyond the $\mathrm{pK}_{\mathrm{a}}$ value (9.2) of boric acid, boric acid (which is neutral and is the 
primary form of boron in the aqueous phase) is deprotonated to form tetrahydroxyborate $259\left(\mathrm{~B}\left(\mathrm{OH}_{4}\right)^{-}\right)$which is a negatively charged species [18]. Rejection of the negatively charged 260 species is governed by both size exclusion and electrostatic interaction mechanisms [31], and 261 thus boron rejection at above pH 9.2 can be significantly higher than that at $\mathrm{pH} 8$ and below 262 (Figure 6b). It is noteworthy that full-scale RO system does not undergo such a high feed $\mathrm{pH}$ 263 (9.5) under normal operation conditions, because full-scale systems are commonly operated at feed $\mathrm{pH}$ of 6-8 to minimise scale formation on membrane surfaces [28].

\subsection{Correlation between boron and NDMA rejection}

The reported results show that the rejection behaviour of NDMA is similar to that of boron. In fact, a strong correlation $\left(\mathrm{R}^{2}=0.90\right)$ between boron and NDMA rejections at various operating conditions was observed (Figure 7). Although boron rejection value was generally similar to NDMA rejection, a large variation in the rejection of these solutes was observed in the clean solution within the range of low rejection values $(<30 \%)$ obtained under different operating conditions. For example, when permeate flux was $10 \mathrm{~L} / \mathrm{m}^{2} \mathrm{~h}$ boron rejection $(8 \%)$ was considerably lower than NDMA rejection (21\%) (Figure 7). In contrast, boron rejection $(11 \%)$ was higher than NDMA rejection (4\%) when feed temperature was $35^{\circ} \mathrm{C}$. Separation performance of neutral and small compounds are dominated partly by the size of passage within the active skin layer of RO membranes (also referred as free-volume hole-radius) [32], and the conformation of polymer matrix within the active skin layer can vary depending on operating conditions (i.e. feed temperature and $\mathrm{pH}$ ) $[29,33]$. Because there is discernible difference in molecular size (e.g. maximum molecular length and molecular width) between boron and NDMA (Table 1), the variation in these rejections can be attributed to the difference in their subjectivity to changes in the conformation of polymer matrix.

\section{[Figure 7]}

\section{3}

\section{Conclusions}

284 We examined the rejection of $\mathrm{N}$-nitrosamines and boron using a pilot-scale reverse osmosis system. There were discernible differences between the rejection values obtained from this pilot-scale study and those previously reported in laboratory-scale studies. These 
discrepancies can be attributed to the high recovery under which the pilot-scale RO system was operated. The rejection of $\mathrm{N}$-nitrosamines and boron by a spiral wound RO membrane system could vary considerably as a function of permeate flux and feed solution temperature.

290 The variation was more significant for small solutes (i.e. boron and low molecular weight N291 nitrosamines such as NDMA, NMEA and NPYR). When permeate flux increased from 10 to $29230 \mathrm{~L} / \mathrm{m}^{2} \mathrm{~h}$, three lowest molecular weight N-nitrosamines (i.e. NDMA and NMEA, NPYR) in 293 the clean solution exhibited a significant increase in rejection (approximately 20\% in 294 rejection value). The two smallest compounds (i.e. NDMA and boron) in the clean solution exhibited a considerable drop in rejection from approximately $40 \%$ to negligible level when feed temperature increased from 10 to $35^{\circ} \mathrm{C}$. The rejection of NDMA and boron in the MF permeate were found to be approximately $20 \%$ higher than those in the clean solution under any feed temperature tested here $\left(10-35^{\circ} \mathrm{C}\right)$. Changes in feed $\mathrm{pH}(5-9.5)$ revealed a negligible impact on the rejection of N-nitrosamines and sodium ions in the clean solution. Nevertheless,

300 boron exhibited a very high rejection $(72 \%)$ at $\mathrm{pH} 9.5$ while boron rejection at the other $\mathrm{pH}$ 301 (5-8) were low (27-32\%). The changes in small solute rejection in response to variation in operating parameters (i.e. permeate flux, temperature, and $\mathrm{pH}$ ) obtained from this pilot-scale study were similar to those from previous laboratory-scale studies. As a result, a strong correlation between the rejections of NDMA and boron was observed. These results confirm that boron rejection can be used as a surrogate for NDMA rejection using spiral wound RO membrane elements. Additional work is recommended to confirm the correlation between NDMA and boron rejections at full-scale plants.

\section{Acknowledgements}

309 This work was supported by the Australian Research Council Linkage Projects LP0990705

310 (with industry support from Veolia Water and Seqwater). The authors acknowledge the 311 University of Wollongong for a PhD scholarship awarded to Takahiro Fujioka.

\section{6. References}

313 [1] M.A. Shannon, P.W. Bohn, M. Elimelech, J.G. Georgiadis, B.J. Marinas, A.M. Mayes, Science and technology for water purification in the coming decades, Nature, 452 (2008) 301-310. 
[2] A.R.D. Verliefde, S.G.J. Heijman, E.R. Cornelissen, G.L. Amy, B. Van der Bruggen, J.C. van Dijk, Rejection of trace organic pollutants with high pressure membranes (NF/RO), Environ. Prog., 27 (2008) 180-188.

[3] Y. Poussade, A. Roux, T. Walker, V. Zavlanos, Advanced oxidation for indirect potable reuse: a practical application in Australia, Water Sci. Technol., 60 (2009) 2419-2424.

[4] M.H. Plumlee, M. López-Mesas, A. Heidlberger, K.P. Ishida, M. Reinhard, Nnitrosodimethylamine (NDMA) removal by reverse osmosis and UV treatment and analysis via LC-MS/MS, Water Res., 42 (2008) 347-355. nanofiltration and reverse osmosis for drinking water augmentation, Journal AWWA, 100 (2008) 102-116.

[6] M.J. Farré, K. Döderer, L. Hearn, Y. Poussade, J. Keller, W. Gernjak, Understanding the operational parameters affecting NDMA formation at Advanced Water Treatment Plants, J. Hazard. Mater., 185 (2011) 1575-1581.

[7] M. Krauss, P. Longrée, F. Dorusch, C. Ort, J. Hollender, Occurrence and removal of N-nitrosamines in wastewater treatment plants, Water Res., 43 (2009) 4381-4391.

[8] M. Krauss, P. Longrée, E. van Houtte, J. Cauwenberghs, J. Hollender, Assessing the fate of Nitrosamine precursors in wastewater treatment by physicochemical fractionation, Environ. Sci. Technol., 44 (2010) 7871-7877.

[9] C. Reyes-Contreras, C. Domínguez, J.M. Bayona, Determination of nitrosamines and caffeine metabolites in wastewaters using gas chromatography mass spectrometry and ionic liquid stationary phases, J. Chromatogr. A, 1261 (2012) 164-170.

[10] S. Yoon, N. Nakada, H. Tanaka, A new method for quantifying N-nitrosamines in wastewater samples by gas chromatography - triple quadrupole mass spectrometry, Talanta, 97 (2012) 256-261.

[11] USEPA, N-Nitrosodimethylamine (CASRN 62-75-9) - Integrated risk information system (IRIS), http://www.epa.gov/iris/subst/0045.htm (1993).

[12] T. Fujioka, L.D. Nghiem, S.J. Khan, J.A. McDonald, Y. Poussade, J.E. Drewes,

[13] T. Fujioka, S.J. Khan, J.A. McDonald, R.K. Henderson, Y. Poussade, J.E. Drewes, 
[15] E. Steinle-Darling, M. Zedda, M.H. Plumlee, H.F. Ridgway, M. Reinhard, Evaluating the impacts of membrane type, coating, fouling, chemical properties and water chemistry on reverse osmosis rejection of seven nitrosoalklyamines, including NDMA, Water Res., 41 (2007) 3959-3967.

[16] C. Bellona, K. Budgell, D. Ball, K. Spangler, J.E. Drewes, S. Chellam, Models to predict organic contaminant removal by RO and NF membranes, IDA Journal, 3 (2011) 40-44.

[17] J.A. McDonald, N.B. Harden, L.D. Nghiem, S.J. Khan, Analysis of N-nitrosamines in water by isotope dilution gas chromatography-electron ionisation tandem mass spectrometry, Talanta, 99 (2012) 146-152.

[18] K.L. Tu, T. Fujioka, S.J. Khan, Y. Poussade, A. Roux, J.E. Drewes, A.R. Chivas, L.D. Nghiem, Boron as a surrogate for N-nitrosodimethylamine (NDMA) rejection by reverse osmosis membranes in potable water reuse applications, Environ. Sci. Technol., 47 (2013) 6425-6430.

[19] K.L. Tu, L.D. Nghiem, A.R. Chivas, Boron removal by reverse osmosis membranes in seawater desalination applications, Sep. Purif. Technol., 75 (2010) 87-101.

[20] N. Hilal, G.J. Kim, C. Somerfield, Boron removal from saline water: A comprehensive review, Desalination, 273 (2011) 23-35.

[21] L. Butterwick, N. de Oude, K. Raymond, Safety assessment of boron in aquatic and terrestrial environments, Ecotoxicol. Environ. Saf., 17 (1989) 339-371.

[22] K.L. Tu, L.D. Nghiem, A.R. Chivas, Coupling effects of feed solution $\mathrm{pH}$ and ionic strength on the rejection of boron by NF/RO membranes, Chem. Eng. J., 168 (2011) $700-706$.

[23] J.G. Wijmans, R.W. Baker, The solution-diffusion model: a review, J. Membr. Sci., 107 (1995) 1-21.

[24] Y. Kiso, K. Muroshige, T. Oguchi, M. Hirose, T. Ohara, T. Shintani, Pore radius estimation based on organic solute molecular shape and effects of pressure on pore radius for a reverse osmosis membrane, J. Membr. Sci., 369 (2011) 290-298.

[25] T. Fujioka, S.J. Khan, J.A. McDonald, A. Roux, Y. Poussade, J.E. Drewes, L.D. Nghiem, N-nitrosamine rejection by nanofiltration and reverse osmosis membranes: The importance of membrane characteristics, Desalination, 316 (2013) 67-75.

[26] A.R.D. Verliefde, E.R. Cornelissen, S.G.J. Heijman, J.Q.J.C. Verberk, G.L. Amy, B. Van der Bruggen, J.C. van Dijk, Construction and validation of a full-scale model for rejection of organic micropollutants by NF membranes, J. Membr. Sci., 339 (2009) $10-20$.

[27] T. Fujioka, S.J. Khan, J.A. McDonald, A. Roux, Y. Poussade, J.E. Drewes, L.D. Nghiem, Modelling the rejection of N-nitrosamines by a spiral-wound reverse 
osmosis system: Mathematical model development and validation, J. Membr. Sci., 454 (2014) 212-219.

[28] T. Fujioka, S.J. Khan, Y. Poussade, J.E. Drewes, L.D. Nghiem, N-nitrosamine removal by reverse osmosis for indirect potable water reuse - A critical review based on observations from laboratory-, pilot- and full-scale studies, Sep. Purif. Technol., 98 (2012) 503-515.

[29] R.R. Sharma, R. Agrawal, S. Chellam, Temperature effects on sieving characteristics of thin-film composite nanofiltration membranes: pore size distributions and transport parameters, J. Membr. Sci., 223 (2003) 69-87.

[30] T. Tsuru, K. Ogawa, M. Kanezashi, T. Yoshioka, Permeation characteristics of electrolytes and neutral solutes through titania nanofiltration membranes at high temperatures, Langmuir, 26 (2010) 10897-10905.

[31] C. Bellona, J.E. Drewes, P. Xu, G. Amy, Factors affecting the rejection of organic solutes during NF/RO treatment - A literature review, Water Res., 38 (2004) 27952809.

[32] T. Fujioka, N. Oshima, R. Suzuki, S.J. Khan, A. Roux, Y. Poussade, J.E. Drewes, L.D. Nghiem, Rejection of small and uncharged chemicals of emerging concern by reverse osmosis membranes: The role of free volume space within the active skin layer, Sep. Purif. Technol., 116 (2013) 426-432.

[33] A.E. Childress, M. Elimelech, Relating nanofiltration membrane performance to membrane charge (electrokinetic) characteristics, Environ. Sci. Technol., 34 (2000) 
412 Table 1: Physicochemical characteristics of the selected N-nitrosamines and boric acid.

\begin{tabular}{|c|c|c|c|c|c|c|c|c|}
\hline Name & $\begin{array}{l}\text { B } \\
\text { (Boric } \\
\text { acid) } \\
\end{array}$ & NDMA & NMEA & NPYR & NDEA & NPIP & NMOR & NDPA \\
\hline Structure & $\mathrm{HO}-\mathrm{B}^{\prime}$ & & $-N=O$ & & & & & \\
\hline $\begin{array}{l}\text { Molecular } \\
\text { Formula }\end{array}$ & $\mathrm{B}(\mathrm{OH})_{3}$ & $\mathrm{C}_{2} \mathrm{H}_{6} \mathrm{~N}_{2} \mathrm{O}$ & $\mathrm{C}_{3} \mathrm{H}_{8} \mathrm{~N}_{2} \mathrm{O}$ & $\mathrm{C}_{4} \mathrm{H}_{8} \mathrm{~N}_{2} \mathrm{O}$ & $\mathrm{C}_{4} \mathrm{H}_{10} \mathrm{~N}_{2} \mathrm{O}$ & $\mathrm{C}_{5} \mathrm{H}_{10} \mathrm{~N}_{2} \mathrm{O}$ & $\mathrm{C}_{4} \mathrm{H}_{8} \mathrm{~N}_{2} \mathrm{O}_{2}$ & $\mathrm{C}_{6} \mathrm{H}_{14} \mathrm{~N}_{2} \mathrm{O}$ \\
\hline $\begin{array}{l}\text { Molecular weight } \\
{[\mathrm{g} / \mathrm{mol}]}\end{array}$ & 61.83 & 74.05 & 88.06 & 100.06 & 102.08 & 114.08 & 116.06 & 130.11 \\
\hline $\begin{array}{l}\text { Maximum } \\
\text { molecular length }{ }^{\text {a }} \\
{[\mathrm{nm}]}\end{array}$ & 0.621 & 0.705 & 0.832 & 0.761 & 0.851 & 0.773 & 0.765 & 1.035 \\
\hline $\begin{array}{l}\text { Molecular width }{ }^{\mathrm{a}} \\
{[\mathrm{nm}]}\end{array}$ & 0.257 & 0.270 & 0.306 & 0.318 & 0.322 & 0.325 & 0.317 & 0.365 \\
\hline $\log K_{o w}{ }^{\mathrm{b}}$ & -0.62 & -0.50 & 0.01 & -0.09 & 0.52 & 0.44 & -0.81 & 1.54 \\
\hline
\end{tabular}

$413{ }^{a}$ Calculated using Molecular Modeling Pro (ChemSW Inc., Fairfield, CA, USA). The maximum molecular length represents the distance 414 between the two most distant atoms in the molecule. The molecular width represents a half of the square root of the area of the rectangle which 415 encloses the projection of the molecule [22].

$416{ }^{\mathrm{b}}$ ACD/PhysChem Suite software (Advanced Chemistry Development, Inc., Ontario, Canada). 
417 Table 2: Measured local flux of each RO element.

\begin{tabular}{cccc}
\hline Average system & \multicolumn{3}{c}{ Local flux ${ }^{\mathrm{a}}\left[\mathrm{L} / \mathrm{m}^{2} \mathrm{~h}\right]$} \\
\cline { 2 - 4 } flux $\left[\mathrm{L} / \mathrm{m}^{2} \mathrm{~h}\right]$ & Lead-element & $2^{\text {nd }}$ element & Tail-element \\
\hline 10 & 11 & 10 & 9 \\
20 & 23 & 19 & 18 \\
30 & 35 & 29 & 27 \\
\hline
\end{tabular}

$418{ }^{\mathrm{a}}$ Experimental conditions are as described in Figure 3. 
419 Table 3: Simulated local flux of lead- and tail-element among seven RO elements.

\begin{tabular}{ccc}
\hline Average system flux & \multicolumn{2}{c}{ Local flux ${ }^{\mathrm{a}}\left[\mathrm{L} / \mathrm{m}^{2} \mathrm{~h}\right]$} \\
\cline { 2 - 3 }$\left[\mathrm{L} / \mathrm{m}^{2} \mathrm{~h}\right]$ & Lead-element & Tail-element \\
\hline 10 & 13 & 7 \\
20 & 25 & 16 \\
30 & 37 & 24 \\
\hline
\end{tabular}

$420{ }^{a}$ Calculated using a software (IMSDesign) provided by Hydranautics (20 $\mathrm{mM} \mathrm{NaCl}, 1 \mathrm{mM}$

$421 \mathrm{NaHCO}_{3}, 1 \mathrm{mM} \mathrm{CaCl}_{2}$, feed $\mathrm{pH} 8.0$, feed temperature $20^{\circ} \mathrm{C}$, system recovery $50 \%$ ). 


\section{LIST OF FIGURES}

423 Figure 1: (a) A picture of the pilot system; and (b) schematic diagram of the pilot system.

424 Figure 2: Rejection of N-nitrosamines and boron in the clean solution by the TFC-HR 425 membrane using the pilot RO system as a function of their molecular weight $(20 \mathrm{mM} \mathrm{NaCl}, 1$ $426 \mathrm{mM} \mathrm{NaHCO}, 1 \mathrm{mM} \mathrm{CaCl}$, average permeate flux $20 \mathrm{~L} / \mathrm{m}^{2} \mathrm{~h}$, feed $\mathrm{pH} 8.0 \pm 0.1$, feed 427 temperature $20.0 \pm 0.1{ }^{\circ} \mathrm{C}$ ). Values reported here are the average and ranges of duplicates 428 results. Open symbols $(\circ$ and $\square)$ represent the rejections of $N$-nitrosamines and boron by the 429 TFC-HR membrane using a laboratory-scale RO filtration setup [12, 18$](20 \mathrm{mM} \mathrm{NaCl}, 1 \mathrm{mM}$ $430 \mathrm{NaHCO}_{3}, 1 \mathrm{mM} \mathrm{CaCl}$, permeate flux $20 \mathrm{~L} / \mathrm{m}^{2} \mathrm{~h}$, feed $\mathrm{pH} 8.0 \pm 0.1$, feed temperature $20.0 \pm$ $\left.4310.1^{\circ} \mathrm{C}\right)$.

432 Figure 3: (a) N-nitrosamine rejection and (b) inorganic solute rejection in the clean solution 433 by the pilot RO system using the TFC-HR membranes as a function of permeate flux (20 mM $434 \mathrm{NaCl}, 1 \mathrm{mM} \mathrm{NaHCO} 3,1 \mathrm{mM} \mathrm{CaCl}_{2}$, feed $\mathrm{pH} 8.0 \pm 0.1$, feed temperature $20.0 \pm 0.1{ }^{\circ} \mathrm{C}$ ). N435 nitrosamine rejection values reported here are the average and ranges of two replicate 436 experiments.

437 Figure 4: (a) N-nitrosamine rejection and (b) inorganic solute rejection in the clean solution 438 by the pilot RO system using the TFC-HR membranes as a function of feed temperature (20 $439 \mathrm{mM} \mathrm{NaCl}, 1 \mathrm{mM} \mathrm{NaHCO} 3,1 \mathrm{mM} \mathrm{CaCl}_{2}$, permeate flux $20 \mathrm{~L} / \mathrm{m}^{2}$ h, feed pH $8.0 \pm 0.1$ ). N440 nitrosamine rejection values reported here are the average and ranges of two replicate 441 experiments.

442 Figure 5: (a) N-nitrosamine rejection and (b) inorganic solute rejection in the MF permeate 443 by the pilot RO system using the TFC-HR membranes as a function of feed temperature 444 (permeate flux $20 \mathrm{~L} / \mathrm{m}^{2} \mathrm{~h}$, feed pH $6.9 \pm 0.1$ ). N-nitrosamine rejection values reported here are 445 the average and ranges of two replicate experiments.

446 Figure 6: (a) N-nitrosamine rejection and (b) inorganic solute rejection in the clean solution 447 by the pilot RO system using the TFC-HR membranes as a function of feed $\mathrm{pH}(20 \mathrm{mM} \mathrm{NaCl}$, $4481 \mathrm{mM} \mathrm{NaHCO}_{3}, 1 \mathrm{mM} \mathrm{CaCl}_{2}$, permeate flux $20 \mathrm{~L} / \mathrm{m}^{2} \mathrm{~h}$, feed temperature $20.0 \pm 0.1{ }^{\circ} \mathrm{C}$ ). N449 nitrosamine rejection values reported here are the average and ranges of two replicate 450 experiments. 
451 Figure 7: Correlation between rejection of boron and NDMA in the (a) clean solution and (b) 452 MF permeate by the pilot RO system using the TFC-HR membranes. Results using the TFC453 HR membrane were obtained from Figure 3-6 with the exclusion of data of feed $\mathrm{pH} 9.5$. 
(a)

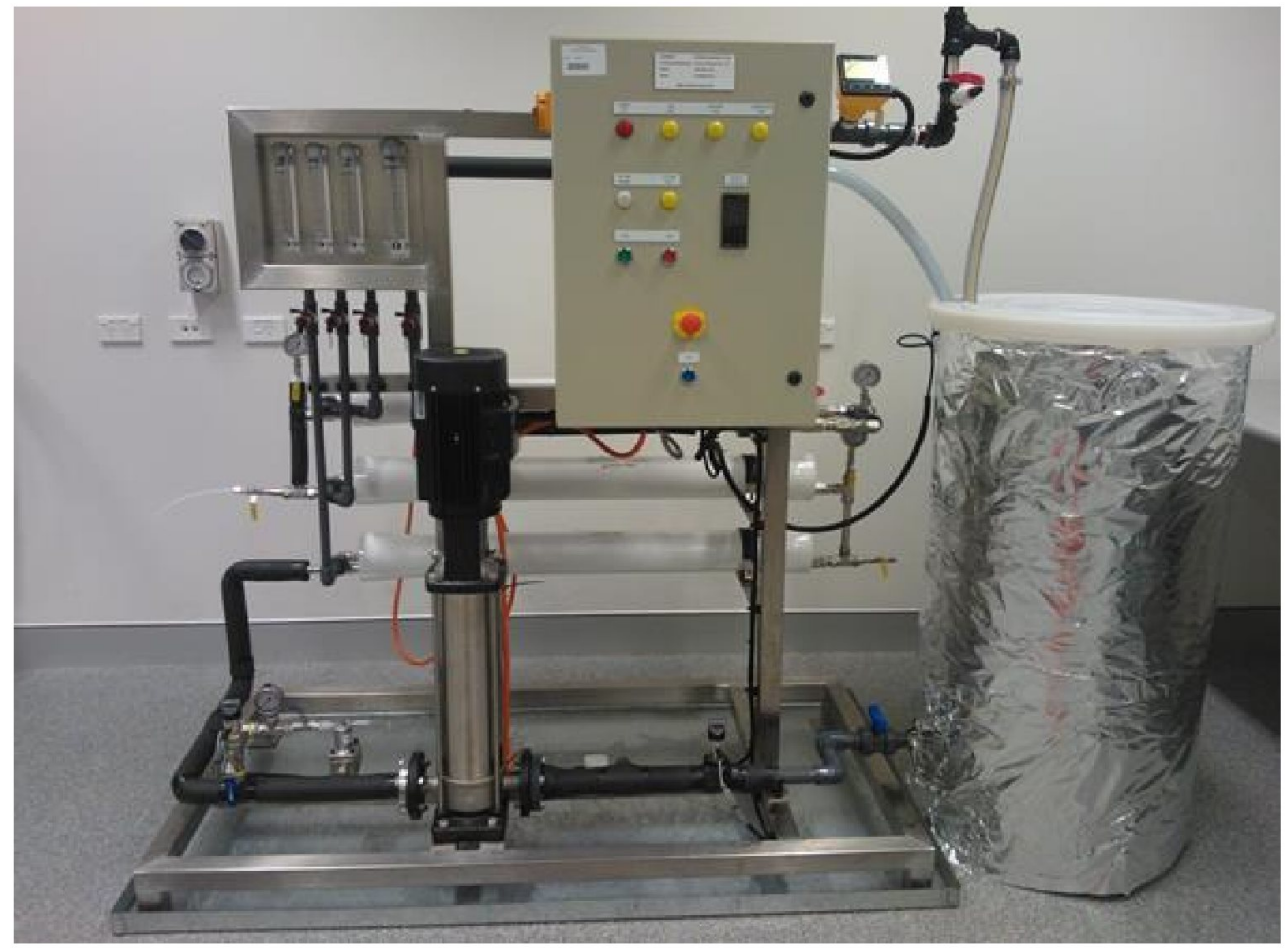

(b)

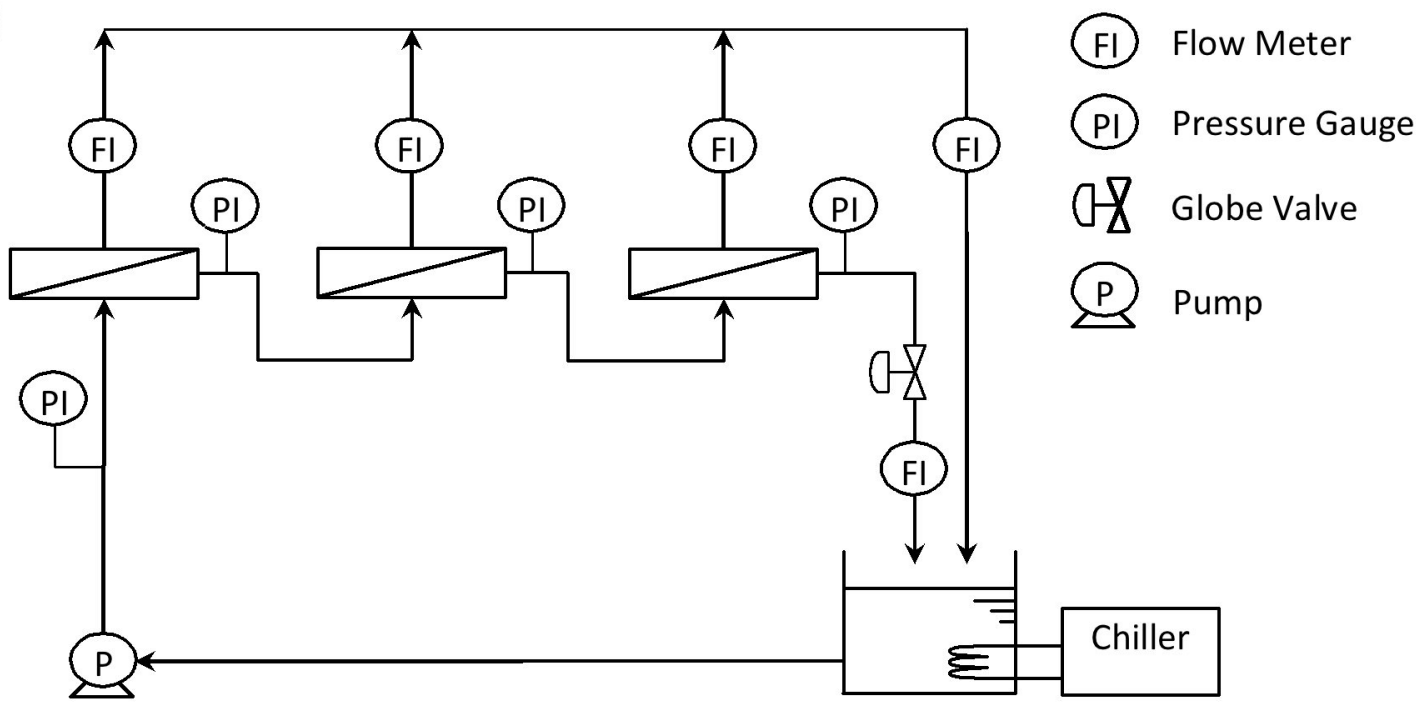

454

455 Figure 1 


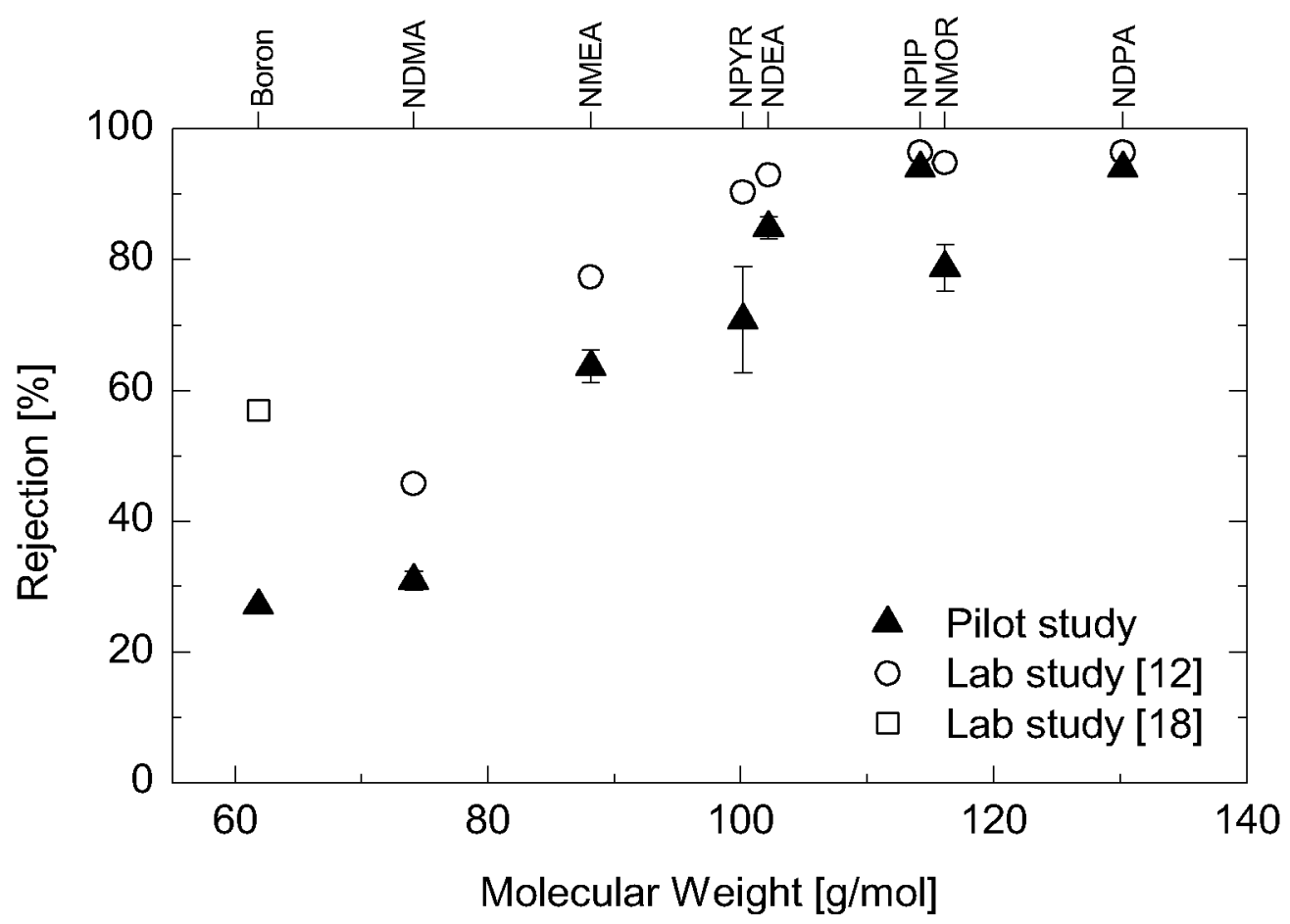

456

457 Figure 2 


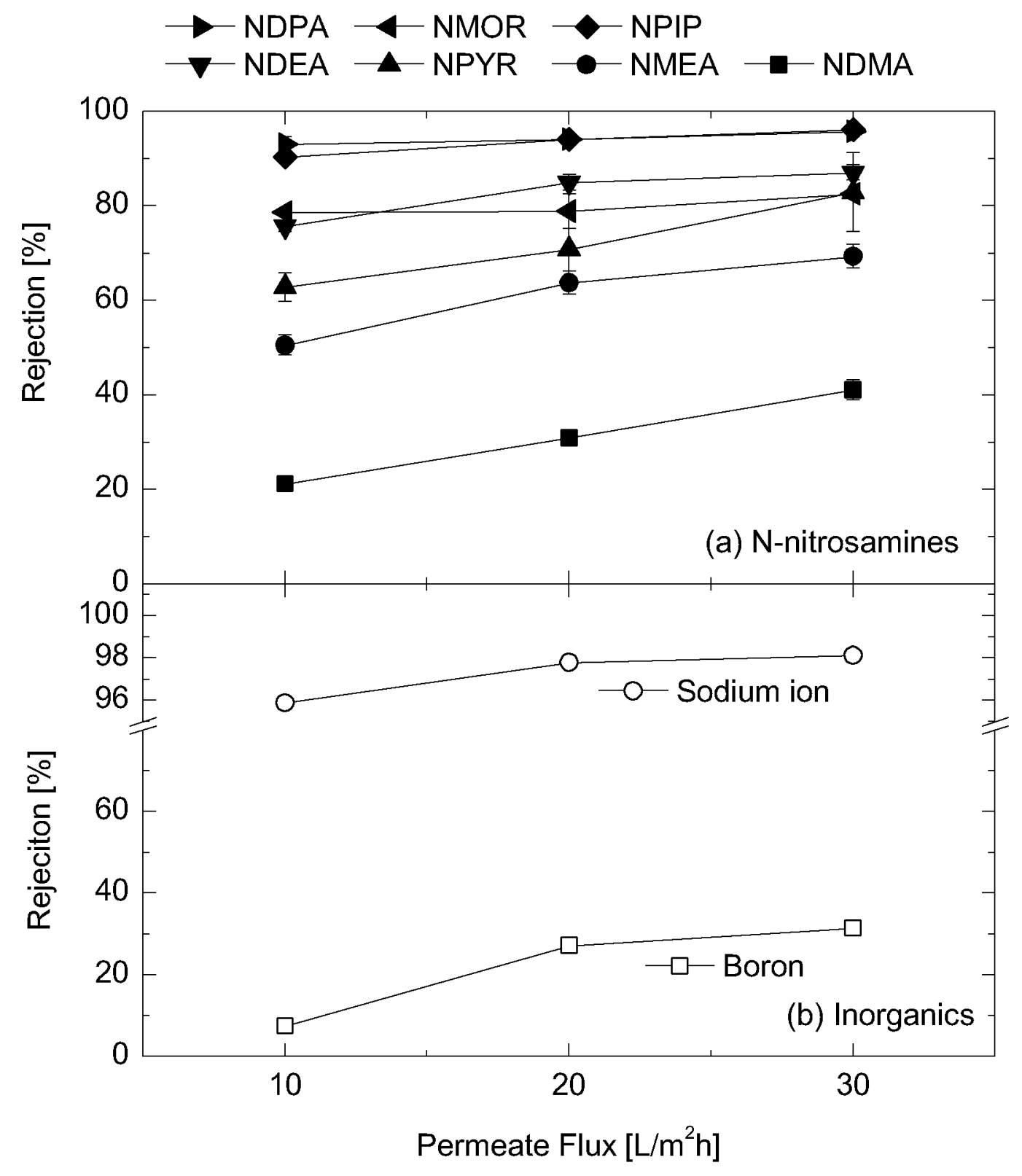

458

459 Figure 3 


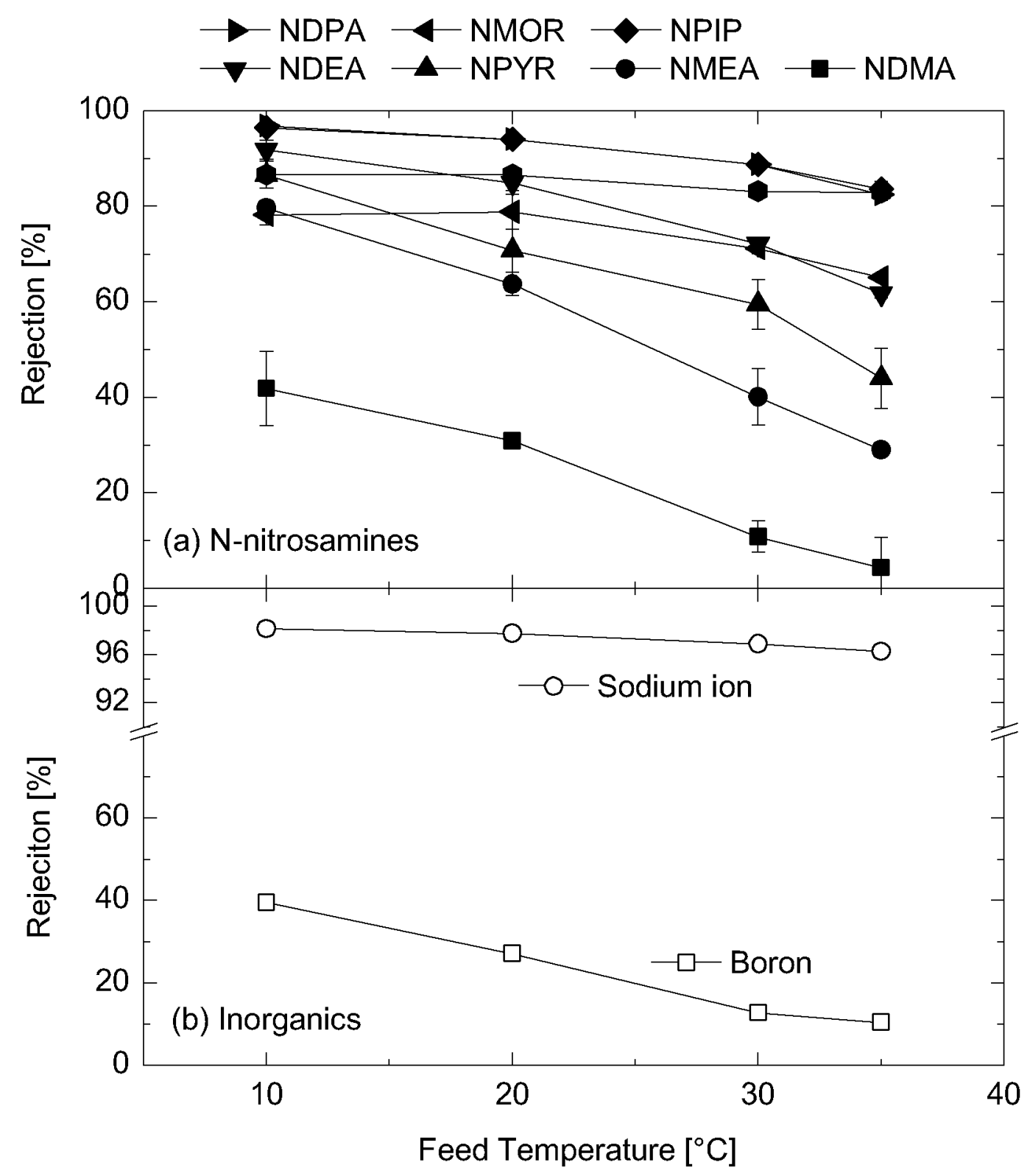

460

$461 \quad$ Figure 4 


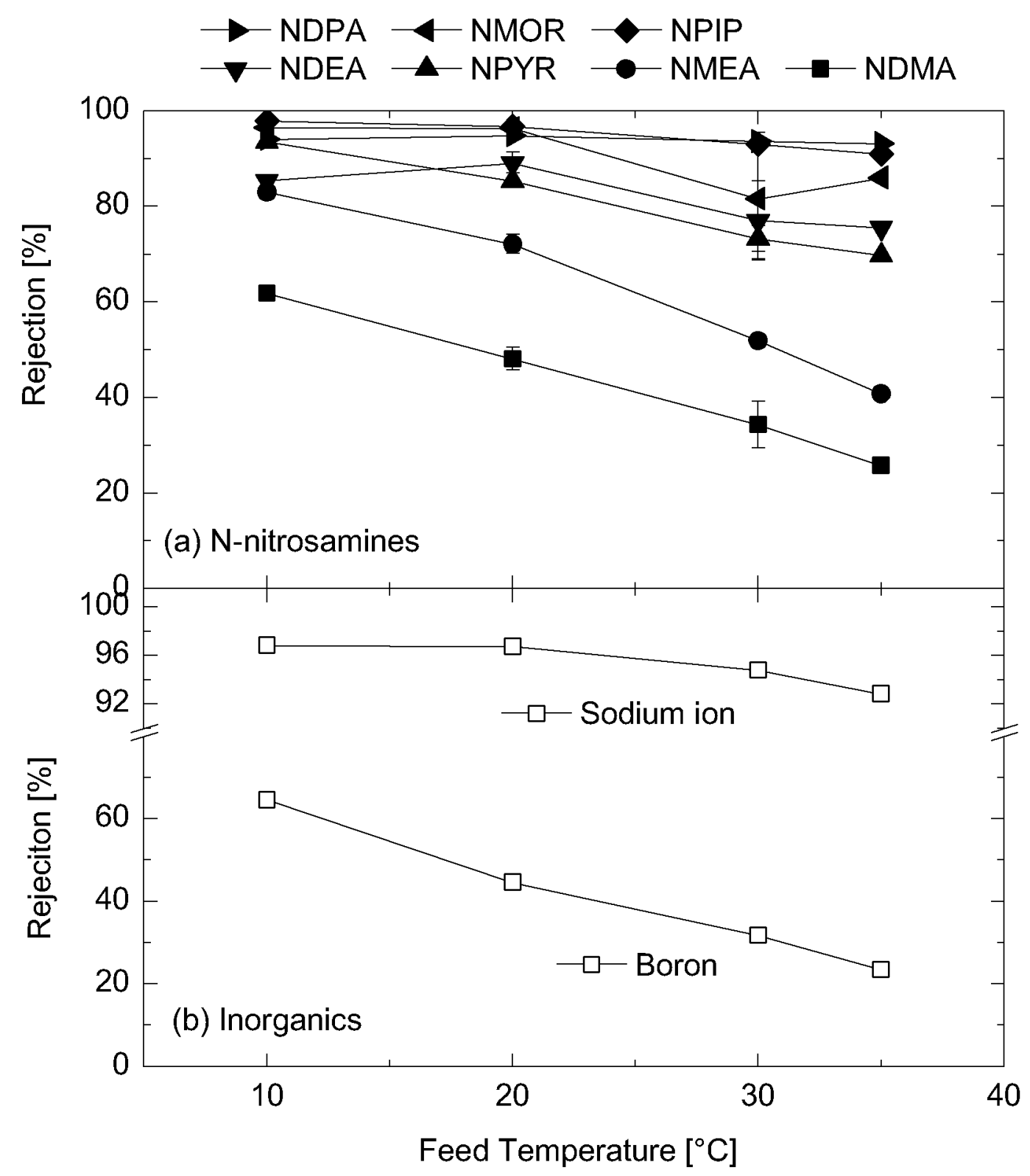

462

$463 \quad$ Figure 5 


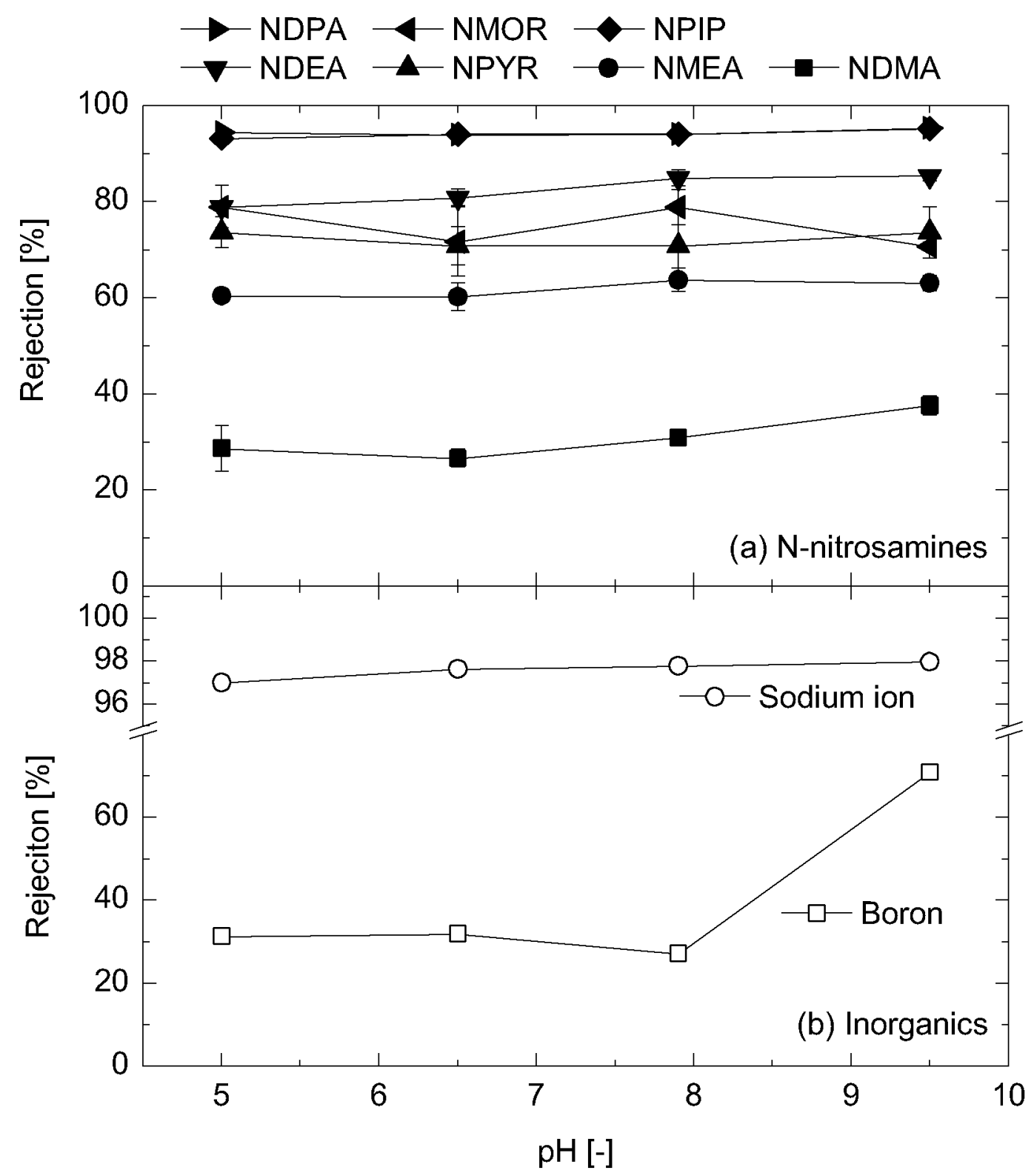

464

$465 \quad$ Figure 6 


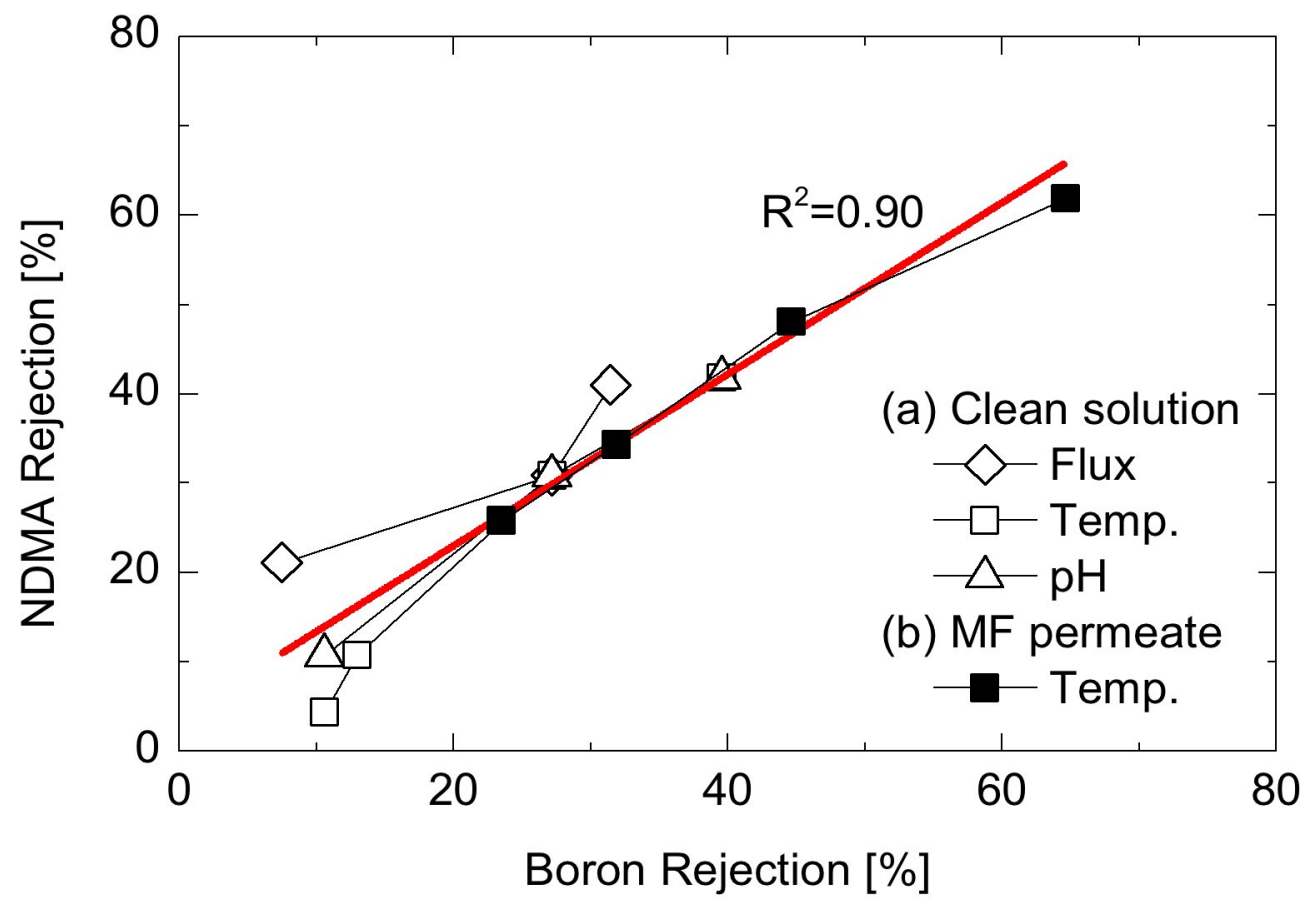

466

$467 \quad$ Figure 7 